\title{
D) $\left[\begin{array}{cl}\sqrt{7} & \text { Diskussionspapiere } \\ \text { Discussion Papers }\end{array}\right.$
}

Discussion Paper No. 260

\section{Vertical Integration and Market Foreclosure with Convex Downstream Costs}

by

Pio Baake*, Ulrich Kamecke** and Hans-Theo Normann*

Berlin, September 2001

* Humboldt-University, Berlin, Department of Economics, Spandauer Strasse 1, D-10178 Berlin, Germany.

** Humboldt-University, Berlin and DIW Berlin, Königin-Luise-Strasse 5, D-14195 Berlin, Germany.

Deutsches Institut für Wirtschaftsforschung, Berlin Königin-Luise-Str. 5, 14195 Berlin

Phone: +49-30-89789- 0

Fax: +49-30-89789- 200

Internet: http://www.diw.de

ISSN 1433-0210 


\title{
Vertical Integration and Market Foreclosure with Convex Downstream Costs*
}

\author{
Pio Baake \\ - Revised Version -
}

\begin{abstract}
In a framework with an upstream monopoly and a downstream duopoly, we analyze the impact of convex costs on the downstream level. In constrast to the case of constant marginal costs, vertical integration does not imply complete market foreclosure. While the nonintegrated downstream firm receives a strictly positive amount of the intermediate good, the downstream allocation is inefficient. However, a parametrized example indicates that competition at the downstream level may increase aggregate welfare.
\end{abstract}

JEL Classification Numbers: C72, C73, D82, L10.

Keywords: Vertical restraints, commitment.

\footnotetext{
${ }^{*}$ We are grateful to Chris Snyder and an anonymous referee for helpful comments.

${ }^{\dagger}$ Humboldt-Universität zu Berlin, Department of Economics, Spandauer Strasse 1, D10178 Berlin, Germany.

${ }^{\ddagger}$ Humboldt-Universität zu Berlin and DIW Berlin, Königin-Luise-Strasse 5, D-14195 Berlin, Germany.

${ }^{\S}$ Humboldt-Universität zu Berlin, Department of Economics, Spandauer Strasse 1, D10178 Berlin, Germany.
} 


\section{Introduction}

Recently, there have been several theoretical papers arguing that vertical integration may have severe anti-competitive effects. These papers, sometimes referred to as new foreclosure theories, include Salinger (1988), Hart and Tirole (1990), and Ordover et al. (1990). In rigorous game-theoretic models, the authors reestablish the more hostile view of vertical integration the "naive" foreclosure theories of the 1950s and 1960s had suggested (see Rey and Tirole, 1997). ${ }^{1}$ They thereby challenge the more benign view of vertical restraints which was adopted since the 1980s following the contributions of the Chicago School (see, e.g., Bork, 1978). ${ }^{2}$

Particularly influential has been the paper of Hart and Tirole (1990). ${ }^{3}$ The core of their analysis ${ }^{4}$ is a commitment problem. Suppose there is an upstream monopolist and two downstream firms. Without vertical integration, the monopolist cannot fully exercise its monopoly power because, once terms are fixed with one downstream firm, the contract with the other downstream firm will be arranged at the disadvantage of the first firm. Since downstream firms will anticipate this kind of opportunistic behavior, the upstream monopolist cannot fully exploit its monopoly position. As a consequence, competition at the downstream level increases social welfare. By contrast, if the upstream monopoly is vertically integrated with one of the downstream firms, it can foreclose the other firm by selling the intermediate

\footnotetext{
${ }^{1}$ Antitrust policy was similarly disapproving of vertical mergers. Leading cases are U.S. v. E.I. duPont de Nemours $\& 3$ Co. 334 U.S. 495, Brown Shoe $\&$ Co. v. U.S. 370 U.S. 294 (1962), and Ford Motor Co. v. U.S. 405 U.S. 562 (1972).

${ }^{2}$ It seems remarkable that vertical mergers are not covered in the 1992 revision of the U.S. Departments of Justice's Merger Guidelines at all.

${ }^{3}$ For closely related papers, see O'Brian and Schaffer (1992), McAfee and Schwartz (1994) and Rey and Tirole (1997). Snyder (1995) contains a survey of empirical tests of the models, and Martin, Normann and Snyder (2001) provide experimental evidence.

${ }^{4}$ We refer to Hart and Tirole's (1990) ex post monopolization variant.
} 
good exclusively to its own downstream firm. Assuming constant marginal costs at the downstream level, Hart and Tirole (1990) show that the vertically integrated firm completely forecloses the nonintegrated firm and restricts output at the monopoly level. Therefore, vertical integration solves the commitment problem. Competition at the downstream level due to the nonintegrated firm does not imply any positive welfare effects.

It is the purpose of this paper to show that these results crucially depend on the assumption of constant marginal costs at the downstream level. Assuming convex marginal costs, we show that vertical integration is not sufficient to overcome the commitment problem and that competition at the downstream level can increase social welfare. With convex marginal costs, complete foreclosure of the nonintegrated downstream firm implies an inefficient allocation of the total output. Distributing the quantity among both downstream firms increases efficiency and hence the monopolist's profit. However, any contract with the nonintegrated downstream firm is still subject to the commitment problem. Once a contract is fixed, the integrated monopolist will set the quantity supplied to its own downstream firm at the disadvantage of the nonintegrated downstream firm. Hence, vertical integration does not fully solve the commitment problem with convex downstream costs. Competition at the downstream level leads to an increase in the quantity supplied and can increase social welfare as compared to the situation where the upstream monopolist can credibly commit to offer the monopoly output.

Our results confirm the concerns of Rey and Tirole (1997, p.21) and Bork (1978, p.228) about the complete foreclosure result in the literature. Rey and Tirole (1997, p.21) note that the complete exclusion of the noninte- 
grated firm is a "drastic consequence" and that supply of the downstream competitor is "a sometimes realistic scenario." Bork (1978, p.228) pointed out the inefficiency of complete foreclosure: "If the marginal costs of retailing are rising - as they certainly are, unless the retailer is a natural monopolistthe artificial low price [offered to the integrated retailer] would result in an increased output at higher costs."

At a more general level, our results show that vertical integration may not be a sufficient instrument for earning monopoly profits. In our model, there is a strict loss of profit from downstream competition even with vertical integration. This is related to the results of Alexander and Reiffen (1995) who show that exclusive territories and resale price maintenance may in fact not have the commitment power the theoretical literature asserts. Similarly, Reiffen (1992) argues that a vertical merger per se is not sufficient in the model of Ordover et al. (1990). All this suggest that vertical integration does not imply monopolization without qualification.

In section 2 we introduce our model and specify the firms' profit functions in three different scenarios. We first consider nonintegration where an upstream monopolist faces two independent downstream firms. In the second scenario, the upstream monopolist is integrated with one of the two downstream firms. In the third scenario, the upstream firm can credibly commit to offer any level of output (e.g. through observable or complete contracts). In section 3, we compare equilibrium outputs for the three scenarios and analyze the impact on profits, consumers' surplus and welfare. We conclude in section 4 . 


\section{The Model}

Consider a market with one upstream firm, $U$, and two downstream firms, $D_{i}, i=1,2$, and suppose that downstream firms compete in quantities. The $q_{i}$ are firms' individual outputs, and $Q=q_{1}+q_{2}$ is industry output. We make the following assumptions:

A1. The inverse demand function, $p(Q)$, is weakly concave with $p^{\prime}(Q)<0$ and $p^{\prime \prime}(Q) \leq 0$.

A2. The upstream firm has convex costs in production $c_{U}(Q)$ with $c_{U}^{\prime}(Q)>0$ and $c_{U}^{\prime \prime}(Q) \geq 0$.

A3. The downstream firms have symmetric convex production costs $c(q)=$ $c_{1}(q)=c_{2}(q)$, with $c(0)=0, c^{\prime}(q)>0$ and $c^{\prime \prime}(q)>0$.

The demand and cost functions are public knowledge. As in Hart and Tirole (1990), we assume that $U$ offers take-it-or-leave-it contracts to the downstream firms. The contracts have the form $\left(q_{i}, T_{i}\right)$, where $q_{i}$ is a certain quantity offered for a fixed tariff $T_{i}$. We will analyze the following three scenarios. First, there is the nonintegrated case $(n)$. Second, there is integration (i) between firm $U$ and firm $D_{1}$. In the third scenario, $U$ can commit $(c)$.

Nonintegration. In this scenario, the upstream firm is not integrated with either of the downstream firms. Contracts are not observable, that is, $\left(q_{i}, T_{i}\right)$ is secretly offered to $D_{i} \cdot{ }^{5}$ Therefore, this is a game of incomplete information. Following Hart and Tirole, we assume that a downstream firm believes that its rival is being offered the equilibrium contract independently of its own contract. After observing an out-of-equilibrium offer, a firm does

\footnotetext{
${ }^{5}$ If contracts were obserable (and not renegotiable), the upstream firm would get monopoly profits even without any further vertical restraint. See the commitment scenario below.
} 
not revise its beliefs about the offer made to its rival (which captures the idea of the possibility of small decision errors). McAfee and Schwartz (1994) call such beliefs passive beliefs. Passive beliefs imply that $U$ considers the two downstream markets separately ("market-by-market conjecture", Rey and Tirole, 1997). ${ }^{6}$

With secret contracts and passive beliefs, downstream firm $i$ accepts any contract $\left(q_{i}, T_{i}\right)$ with $T_{i} \leq \pi_{i}\left(q_{i}, \tilde{q}_{j}\right)$, where $\tilde{q}_{j}$ with $j=1,2, i \neq j$ denotes the candidate equilibrium quantity of $D_{j}$ and $\pi_{i}\left(q_{i}, \tilde{q}_{j}\right)=p\left(q_{i}+\tilde{q}_{j}\right) q_{i}-c_{i}\left(q_{i}\right)$ is downstream firm $i$ 's gross profit. It follows that $U$ chooses $T_{i}=\pi_{i}\left(q_{i}, \tilde{q}_{j}\right)$ and $q_{i}$ such that

$$
q_{i}=\arg \max _{q}\left[\pi_{i}\left(q, \widetilde{q}_{j}\right)-c_{U}\left(q+\widetilde{q}_{j}\right)\right] .
$$

Since (1) must hold for both downstream firms, the quantities offered in a perfect Bayesian Nash equilibrium must satisfy the mutual best response property, i.e., they must constitute a Cournot-Nash equilibrium. Our above assumptions guarantee that the reaction functions $q_{i}^{*}\left(q_{j}\right)$ defined by ${ }^{7}$

$$
\frac{\partial \pi_{i}\left(q_{i}, q_{j}\right)}{\partial q_{i}}=\frac{\partial}{\partial q_{i}}\left[p q_{i}-c_{i}-c_{U}\right]=p^{\prime} q_{i}+p-c_{i}^{\prime}-c_{U}^{\prime}=0
$$

are downward sloping with $q_{i}^{* \prime} \in(-1,0)$. Therefore, a unique Cournot-Nash equilibrium quantity solving $q^{n}=q_{i}^{*}\left(q^{n}\right)$ exists. The unique perfect Bayesian equilibrium is given by $U$ offering $\left(q^{n}, T^{n}\right)$ to both downstream firms with $T^{n}:=\pi_{i}\left(q^{n}, q^{n}\right)$. Let $Q^{n}:=2 q^{n}$ denote industry output.

Integration. We assume that the integrated firm $U-D_{1}$ cannot credibly commit to produce a certain quantity $q_{1}$ prior to offering any contract $\left(q_{2}, T_{2}\right)$ to $D_{2}$. To determine the optimal contract we consider two cases. First, $D_{2}$

\footnotetext{
${ }^{6}$ See also O'Brian and Schaffer (1992). Alternative beliefs lead to other equilibria. For example, McAfee and Schwartz (1994) show that symmetric beliefs lead to the monopoly outcome without vertical restraints.

${ }^{7}$ To simplify the notation, we often omit arguments in the following.
} 
accepts the contract and supplies $q_{2}$. Second, $D_{2}$ accepts the contract but supplies a quantity $\widehat{q}_{2}$ smaller than $q_{2}$. In the first case, the optimal quantity $q_{1}^{*}$ of firm $U-D_{1}$ is

$$
q_{1}^{*}\left(q_{2}\right)=\arg \max _{q_{1}}\left[\pi_{1}\left(q_{1}, q_{2}\right)-c_{U}\left(q_{1}+q_{2}\right)\right] .
$$

Anticipating $q_{1}^{*}\left(q_{2}\right), D_{2}$ will accept the contract $\left(q_{2}, T_{2}\right)$ and will supply $q_{2}$ if

$$
\begin{aligned}
& T_{2} \leq \pi_{2}\left(q_{2}, q_{1}^{*}\left(q_{2}\right)\right) \\
& q_{2} \leq \arg \max _{\widetilde{q}_{2}} \pi_{2}\left(\widetilde{q}_{2}, q_{1}^{*}\left(\widetilde{q}_{2}\right)\right)
\end{aligned}
$$

holds. Suppose (5) holds. With $T_{2}=\pi_{2}\left(q_{2}, q_{1}^{*}\left(q_{2}\right)\right)$ the reduced profit function $\pi^{i}\left(q_{2}\right)$ of firm $U-D_{1}$ can be written as

$$
\pi^{i}\left(q_{2}\right)=p\left(q_{2}+q_{1}^{*}\right)-c_{1}-c_{2}-c_{U}
$$

Using the envelope theorem, the Kuhn-Tucker conditions for the optimal quantity $q_{2}^{i}$ are

$$
\pi^{i \prime}\left(q_{2}\right)=p^{\prime}\left[q_{1}^{*}+q_{2}\left(1+q_{1}^{* \prime}\right)\right]+p-c_{2}^{\prime}-c_{U}^{\prime} \leq 0 \text { and } \pi^{i \prime} \cdot q_{2}=0 .
$$

Since $q_{1}^{* \prime}>-1$, it follows form (3) and (7) that $q_{1}^{*}\left(q_{2}^{i}\right)>q_{2}^{i}$ and

$$
\frac{\partial \pi_{2}}{\partial q_{2}}-\pi^{i \prime}\left(q_{2}^{i}\right)=-p^{\prime}\left(q_{1}^{*}+q_{2}^{i} q_{1}^{* \prime}\right)+c_{U}^{\prime}>0
$$

Therefore, if $U$ - $D_{1}$ offers $\left(q_{2}^{i}, \pi_{2}\left(q_{2}^{i}, q_{1}^{*}\left(q_{2}^{i}\right)\right)\right), D_{2}$ supplies $q_{2}^{i}$ and industry output is given by $Q^{i}:=q_{1}^{*}\left(q_{2}^{i}\right)+q_{2}^{i}$.

Turning to the second case, assume that $U$ - $D_{1}$ offers a contract $\left(q_{2}, T_{2}\right)$ such that $D_{2}$ accepts the contract but supplies a quantity $\widehat{q}_{2}<q_{2}$. Then, the supplied quantities are characterized by

$$
\begin{aligned}
\widehat{q}_{2}\left(q_{2}\right) & =\arg \max _{\widetilde{q}_{2}} \pi_{2}\left(\widetilde{q}_{2}, \widehat{q}_{1}\left(\widetilde{q}_{2}, q_{2}\right)\right) \\
\text { with } \widehat{q}_{2} & <q_{2} \text { and } \widehat{q}_{1}\left(\widetilde{q}_{2}, q_{2}\right)=\arg \max _{q_{1}}\left[\pi_{1}\left(q_{1}, \widetilde{q}_{2}\right)-c_{U}\left(q_{1}+q_{2}\right)\right] .
\end{aligned}
$$


Comparing the necessary conditions for $\widehat{q}_{2}\left(q_{2}\right)$ and $\widehat{q}_{1}\left(\widetilde{q}_{2}, q_{2}\right)$ shows that $D_{2}$ would supply $\widehat{q}_{1}$ if $U-D_{1}$ had offered a (accepted) contract with $\widehat{q}_{1}$ instead of $q_{2}$. Furthermore, using $(3)$ reveals $q_{1}^{*}\left(\widehat{q}_{1}\right)<\widehat{q}_{2}$. Hence, $U-D_{1}$ could increase its profit by offering $\left(\widehat{q}_{1}, \pi_{2}\left(\widehat{q}_{1}, q_{1}^{*}\left(\widehat{q}_{1}\right)\right)\right)$ instead of $\left(q_{2}, T_{2}\right)$ with $T_{2} \leq$ $\pi_{2}\left(\widehat{q}_{2}, \widehat{q}_{1}\left(\widehat{q}_{1}, q_{2}\right)\right)$. Therefore, any contract with $q_{2}>\widehat{q}_{2}\left(q_{2}\right)$ can not be optimal and the equilibrium is characterized by $\left(q_{2}^{i}, \pi_{2}\left(q_{2}^{i}, q_{1}^{*}\left(q_{2}^{i}\right)\right)\right)$ and $Q^{i}$.

Commitment. In this scenario, we assume that $U$ can credibly commit to any output level. A simple commitment device are observable contracts (McAfee and Schwartz, 1994). ${ }^{8}$ Observability implies that each downstream firm knows the quantity offered to the other firm when deciding on accepting its own contract. Hence, in a subgame perfect equilibrium, firm $i$ will accept any offer $\left(q_{i}, T_{i}\right)$ with $T_{i} \leq \pi_{i}\left(q_{i}, q_{j}\right)$. $U$ will choose $T_{i}=\pi_{i}\left(q_{i}, q_{j}\right)$ and the quantities such that total industry profits

$$
\pi^{c}=p\left(q_{1}+q_{2}\right)-c_{1}-c_{2}-c_{U}
$$

are maximized. Let denote $q^{c}$ the quantity which solves

$$
\left.\frac{\partial \pi^{c}}{\partial q_{i}}\right|_{q_{i}=q_{j}}=2 p^{\prime} q^{c}+p-c_{i}^{\prime}-c_{U}^{\prime}=0 .
$$

Convexity and symmetry of the cost functions imply that $U$ offers $q^{c}$ to both downstream firms $D_{1}$ and $D_{2}$. Total industry output is given by $Q^{c}:=2 q^{c}>$ $Q^{n}$.

\section{The Results}

We start by analyzing the impact of vertical integration on output.

\footnotetext{
${ }^{8}$ Other commitment devices are complete contracts (in which the price of the intermediate good can be made contingent upon the final good price) or integration with both downstream firms.
} 
Proposition 1 With vertical integration, the nonintegrated downstream firm receives $q_{2}^{i}>0$ and the integrated downstream firm receives $q_{1}^{*}\left(q_{2}^{i}\right)>q^{n}$. Industry output $Q^{i}$ is greater than in the commitment scenario but smaller than in the nonintegration case, i.e., $Q^{i} \in\left(Q^{c}, Q^{n}\right)$.

Proof. We first show that $q_{2}^{i}>0$. Note that $q_{1}^{*}(0)<2 q^{c}$ :

$$
\left.\frac{\partial \pi_{1}}{\partial q_{1}}\right|_{q_{2}=0, q_{1}=2 q^{c}}=2 p^{\prime} q^{c}+p-c_{1}^{\prime}-c_{U}^{\prime}<0
$$

from (10) and $c_{1}^{\prime}\left(2 q^{c}\right)>c_{1}^{\prime}\left(q^{c}\right)$. Therefore some $q_{2} \in\left(0, q^{c}\right)$ exists for which $q_{2}+q_{1}^{*}\left(q_{2}\right)=2 q^{c}$. Call this quantity $q_{2}^{k}$, i.e., $q_{2}^{k}:=\left\{q_{2} \mid q_{2}+q_{1}^{*}\left(q_{2}\right)=2 q^{c}\right\}$. Again using (10), we get

$$
\left.\frac{\partial \pi^{i}}{\partial q_{2}}\right|_{q_{2}=q_{2}^{k}}=p^{\prime}\left[q_{1}^{*}+q_{2}^{k}\left(1+q_{1}^{* \prime}\right)\right]+p-c_{2}^{\prime}-c_{U}^{\prime}=p^{\prime} q_{2}^{k} q_{1}^{* \prime}+\left.c^{\prime}\right|_{q=q^{c}}-c_{2}^{\prime}>0
$$

where the last inequality follows from $p^{\prime} q_{2}^{k} q_{1}^{* \prime}>0$ and $q_{2}^{k}<q^{c}$. Hence, we get $Q^{i}>Q^{c}$ and $q_{2}^{i}>0$. Using (2), we obtain

$$
\left.\frac{\partial \pi^{i}}{\partial q_{2}}\right|_{q_{2}=q^{n}}=p^{\prime}\left[q^{n}+q^{n}\left(1+q_{1}^{* \prime}\right)\right]+p-c_{2}^{\prime}-c_{U}^{\prime}=p^{\prime} q^{n}\left(1+q_{1}^{* \prime}\right)<0
$$

which yields $q_{1}^{*}\left(q_{2}^{i}\right)>q^{n}$ and so $Q^{i}<Q^{n}$.

With integration and convex downstream costs, the nonintegrated downstream firm receives a strictly positive quantity. Note that constant marginal costs, i.e., $c_{1}^{\prime \prime}=c_{2}^{\prime \prime}=0$, and (10) would yield $q_{2}^{i}=0$ and $q_{1}^{*}=2 q^{c}$. Convex downstream costs imply that $q_{2}=0$ results in a highly inefficient allocation which forces $U-D_{1}$ to choose $q_{2}^{i}>0$. The monopolist's commitment problem then implies that total industry output is increased compared to the commitment case.

Concerning consumers' surplus $(C S)$ and the upstream firm's profits, Proposition 1 leads to the following 
Corollary For consumers' surplus, $C S^{n}>C S^{i}>C S^{c}$ holds, while for U's profit $\pi^{c}>\pi^{i}>\pi^{n}$ holds.

Proof. $C S^{n}>C S^{i}>C S^{c}$ follows simply from $Q^{n}>Q^{i}>Q^{c}$. In the commitment scenario, industry profits are maximized. Since $Q^{i}>Q^{c}$ we obtain $\pi^{c}>\pi^{i}$. Because $\pi^{n}$ is feasible with integration, but as seen in the proof of Proposition 1, $\partial \pi^{i} / \partial q_{2}<0$ at $q_{2}=q_{2}^{n}$, it follows that $\pi^{i}>\pi^{n}$.

Finally, we consider the implication on welfare. When comparing $W^{i}$ and $W^{c}$, we have $Q^{i}>Q^{c}$ (suggesting an increase in welfare), but there is an efficiency loss in production with integration. In that case the general implications for welfare are ambiguous and, therefore, we can only analyze a parametrized model.

Proposition 2 For total welfare, $W^{n}>W^{i}$ and $W^{n}>W^{c}$ holds. For linear demand and linear-quadratic costs, we get $W^{i}>W^{c}$.

Proof. $W^{n}>W^{c}$ follows from $Q^{n}>Q^{c}$ and $p\left(2 q^{n}\right)>c^{\prime}\left(q^{n}\right)+c_{U}^{\prime}\left(2 q^{n}\right)$. Similarly, $W^{n}>W^{i}$ follows from $Q^{n}>Q^{i}$ where, in addition, production of $Q^{i}$ is inefficient.

To prove $W^{i}>W^{c}$ for linear demand and linear-quadratic costs, assume that $p(Q)=1-Q$ and that $c_{U}(Q)=0.5 \alpha Q^{2}$ and $c(q)=0.5 \beta q^{2}$ with $\alpha, \beta>$ $0 .{ }^{9}$ It is straightforward to derive $q^{c}=1 /(4+2 \alpha+\beta), \pi^{c}=1 /(4+2 \alpha+\beta)$, and $C S^{c}=2 /(4+2 \alpha+\beta)^{2}$. Further, $q_{1}^{*}\left(q_{2}\right)=\left(1-q_{2}(1+\alpha)\right) /(2+\alpha+\beta)$. Maximizing (6) for this parametrization yields

$$
q_{2}^{i}=\frac{\beta}{1+\beta(4+2 \alpha+\beta)},
$$

\footnotetext{
${ }^{9}$ Using $p(Q)=a-b Q, c_{U}(Q)=\alpha_{1} Q+0.5 \alpha_{2} Q^{2}$ and $c(q)=\beta_{1} q+0.5 \beta_{2} q^{2}$ with all parameters being positive would not change our results. The additional parameters $a, b, \alpha_{1}$ and $\beta_{1}$ would only clutter the analysis.
} 


$$
q_{1}^{*}\left(q_{2}^{i}\right)=\frac{1+\beta(3+\alpha+\beta)}{(2+\alpha+\beta)(1+\beta(4+2 \alpha+\beta))} .
$$

Note that for $\alpha=\beta=0$, the constant marginal (zero) cost equilibrium results: $q_{2}^{i}=0$ and $q_{1}^{*}(0)=0.5$. We obtain

$$
\begin{aligned}
\pi^{i} & =\frac{1+2 \beta(2+\alpha+\beta)}{2(2+\alpha+\beta)(1+\beta(4+2 \alpha+\beta))} \\
C S^{i} & =\frac{\left(1+\beta(5+2 \alpha+2 \beta)^{2}\right.}{2(2+\alpha+\beta)^{2}(1+\beta(4+2 \alpha+\beta))^{2}}
\end{aligned}
$$

Finally, regarding $\Delta W=W^{i}-W^{c}$, simple but tedious calculation shows that

$$
\Delta W:=\left(C S^{i}+\pi^{i}\right)-\left(C S^{c}+\pi^{c}\right)>0 \forall \alpha, \beta>0 \text { and } \lim _{\beta \rightarrow 0} \Delta W=0
$$

holds. $\square$

\section{Conclusion}

In this paper, we analyze a model of vertical integration allowing for convex cost functions at the downstream level. As a result, the nonintegrated downstream firm sells a strictly positive quantity. Since the integrated downstream firm receives a larger quantity, the downstream allocation is inefficient. However, compared to the scenario in which the upstream firm can credibly commit, aggregate output increases. For linear demand and linearquadratic costs, this increase in output is sufficient to more than compensate the efficiency loss in production. In such cases, welfare increases.

Our results suggest that upstream monopolists, choosing among various vertical contractual arrangements, should actually look for devices which enable to fully commit themselves (e.g. publicly observable contracts) rather than to integrate downwards. In our model, upstream monopolists are only 
indifferent between integration and such a commitment device when the downstream industry exhibits constant marginal costs. On a policy level, however, this does by no means imply that vertical integration is harmless. Though the nonintegrated downstream firm is not completely foreclosed when cost functions are convex, there is market foreclosure in the sense of reduced output, compared to the vertically unrestricted market. In addition, there are inefficiencies in the downstream allocation with integration, so, generally, welfare is reduced.

\section{References}

Alexander, C., and Reiffen, D. (1995): Vertical Contracts as Strategic Commitments: How are They Enforced?, Journal of Economics and Management Strategy, 4, 623-649.

Bork, R. (1978): Antitrust Paradox, New-York: Basic Books.

Hart, O. and Tirole, J. (1990): Vertical Integration and Market Foreclosure, Brookings Papers on Economic Activity: Microeconomics, 205-276.

Martin, S., Normann, H.T. and Snyder, C.M. (2001): Vertical Foreclosure in Experimental Markets, forthcoming in: RAND Journal of Economics.

McAfee, R.P. and Schwartz, M. (1994): Opportunism in Multilateral Vertical Contracting: Nondiscrimination, Exclusivity, and Uniformity, American Economic Review, 84, 210-230.

O'Brien, D. P. and Shaffer, G. (1992): Vertical Control with Bilateral Contracts, RAND Journal of Economics, 23, 299-308.

Ordover, J.A., Saloner, G., and Salop, S.C. (1990): Equilibrium Vertical Foreclosure, American Economic Review, 80, 127-42.

Reiffen, D. (1992): Equilibrium Vertical Foreclosure: Comment, American Economic Review, 82, 694-97.

Rey, P. and Tirole, J. (1997): A Primer on Foreclosure, Handbook of Industrial Organization, Vol. 3 (forthcoming).

Salinger, M. (1988): Vertical Mergers and Market Foreclosure, The Quarterly Journal of Economics, 103, 345-356.

Snyder, C.M. (1995): Empirical Studies of Vertical Foreclosure, Industry Economics Conference papers and Proceedings, University of Melbourne and Bureau of Industry Economics, 23, 98-127. 